P. V. Nannan Panday

P. Vischjager

M. G. G. Rodgers

J. M. Maurer

M. G. G. Sturkenboom

M. W. N. Nijsten

\section{Rifampicin treatment of persistently elevated benzodiazepine metabolites in a comatose patient}

Accepted: 20 April 2009

Published online: 17 June 2009

(C) The Author(s) 2009. This article is published with open access at

Springerlink.com

After taking 35 tablets of flurazepam $15 \mathrm{mg}, 50$ tablets of diazepam $5 \mathrm{mg}$, a 38-year old female $(105 \mathrm{~kg}$, BMI
36) was hit by a vehicle at $80 \mathrm{~km} / \mathrm{h}$. Initially she had a coma that measured a 1-4-2 on the Glasgow Coma Scale (GCS), an impression fracture of the frontal bone with free air in cerebro, a right-sided frontal contusion and a mild traumatic subarachnoidal bleed. Several ribs on her right were broken without any injury to the organs. After a decompressive craniotomy, she was admitted to the ICU.

At the time of admission, flurazepam $(124 \mu \mathrm{g} / \mathrm{L}$; therapeutic range 40 $150 \mu \mathrm{g} / \mathrm{L}[1,2])$ and diazepam serum levels were therapeutic $(439 \mu \mathrm{g} / \mathrm{L}$; therapeutic range $100-750 \mu \mathrm{g} / \mathrm{L}$ $[1,2])$. The active metabolite of diazepam, desmethyldiazepam, was toxic $(5,971 \mu \mathrm{g} / \mathrm{L}$; therapeutic range: 200 $1,800 \mu \mathrm{g} / \mathrm{L}[2])$. The other metabolites temazepam and oxazepam were low.

Fentanyl and propofol, administered for analgesia and sedation, were

Time course of benzodiazepins before and after rifampicin administration

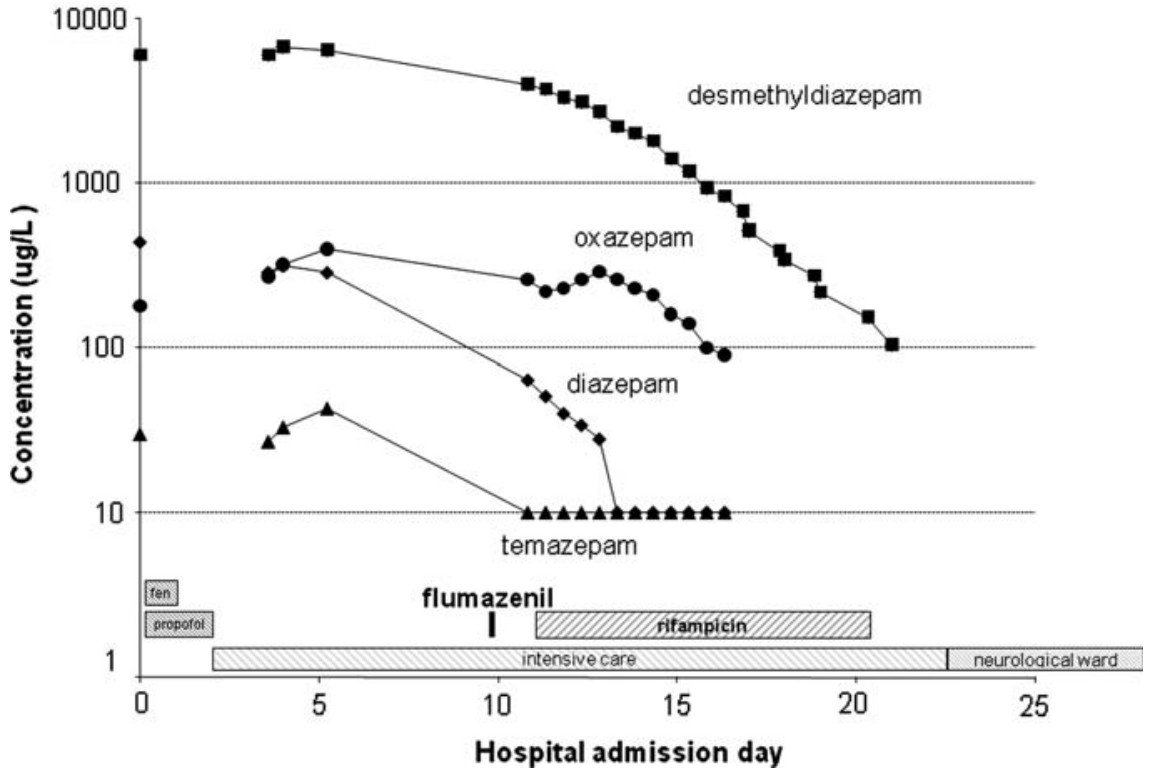

Fig. 1 Time course of benzodiazepine serum levels before and during rifampicin administration (fen fentanyl). Except for a brief period directly after ICU-admission, the patient received no benzodiazepines or other sedatives, narcotics or analgesics. Due to high levels and a challenge with Flumazenil demonstrated benzodiazepine intoxication, rifampicin was started. After start of rifampicin, clearance of the metabolites was accelerated, as indicated by the increasing decline of the metabolite concentration curves

stopped after 2 days; the patient received no other medication. A CT cerebrum was repeated on day 5 and revealed diffuse contusions. An electroencephalogram indicated diffuse encephalopathy. These findings were considered insufficient to explain her persistent coma. Desmethyldiazepam serum level remained high, despite the patients' normal liver and kidney function. Flumazenil was administered, revealing a coma of 4 -3-T on the GCS. As elimination of desmethyldiazepam seemed to be impaired, genotyping was performed. This revealed that she was an extensive cytochrome P450 (CYP) 2C19 metaboliser. To enhance elimination, rifampicin, a CYP3A4 and 2C19 inducer, $600 \mathrm{mg}$ bid i.v., was started on day 12 (Fig. 1).

When the serum level of desmethyldiazepam had fallen within therapeutic ranges at day 20 , the patient improved. After 34 days she was transferred to a neurological medium care facility. Four months after her hospital discharge, she had a maximal GCS and was still recovering from her injuries.

This case underscores two points. First, diazepam and its active metabolites can considerably prolong coma. This is due to the metabolic pathway of diazepam [6]. Diazepam is metabolized through CYP3A4 to temazepam and CYP3A4/2C19 to desmethyldiazepam which is then metabolized through CYP3A4 to oxazepam. Temazepam and oxazepam, which have a small effect compared to diazepam and desmethyldiazepam are eliminated through conjugation. The high levels of desmethyldiazepam and low levels of temazepam and oxazepam underscore impairment of CYP3A4/2C19. In benzodiazepine intoxications, focus on withdrawal and clearance of all active metabolites is advisable.

Second, rifampicin accelerated clearance of the metabolites through induction of CYP2C19 and CYP3A4. 
The elimination half-life of desmethyldiazepam decreased from $194 \mathrm{~h}$ (normal range 40-200 $\mathrm{h}$ [5]) to 63 after start of rifampicin and may have shortened the comatose condition by 20 days. We preferred to use rifampicin for several reasons. Rifampicin is a well-characterised drug with established strong CYP3A4/ 2C19 inducing capabilities. Furthermore, the FDA [3, 4] considers rifampicin as the drug of choice for CYP450 inducer studies. Finally, other CYP3A4 inducers like antiretroviral agents and anti-epileptics have shortcomings like the advisable restricted use for HIV treatment and neurological side effects that could have complicated assessment of our patient or even provoked convulsions.

We suggest that rifampicin may be considered in severe benzodiazepine intoxications if clearance of the drug appears to be problematic. Obviously, other drug interactions and development of rifampicin resistance should be kept in mind.

Open Access This article is distributed under the terms of the Creative Commons
Attribution Noncommercial License which permits any noncommercial use, distribution, and reproduction in any medium, provided the original author(s) and source are credited.

\section{References}

1. Dollery CT (ed) (1999) Therapeutic drugs, 2nd edn. Churchill Livingstone, Edinburgh, pp D169-D173

2. Anthony C, Osselton MD, Widdop B (eds) (2004) Clarke's analysis of drugs and poisons, 3rd edn. Pharmaceutical Press, London, pp 943-944

3. Flockhart DA (2007) Drug Interactions: cytochrome P450 drug interaction table. Indiana University School of Medicine. http://medicine.iupui.edu/flockhart/ table.htm. Accessed 28 May 2008

4. FDA (2006) Drug development and drug interactions: table of substrates, inhibitors and inducers. http://www.fda.gov/cder/drug/ drugInteractions/tableSubstrates.htm. Accessed 28 May 2008

5. Drugdex ${ }^{\circledR}$ Evaluations. Diazepam drug information. MICROMEDEX ${ }^{\circledR}$ Healthcare Series, Thomson Reuters, USA
6. Inamoto Nagashima A, Itagaki F, Homma M, Nishimura M, Osaka Y, Okuyama K, Tanaka E, Nakamura T, Kohda Y, Naito S, Miyabe M, Toyooka H (2005) CYP2C19 genotype affects diazepam pharmacokinetics and emergence from general anesthesia. Clin Pharmacol Ther 78:647-655

P. V. N. Panday $(\bowtie) \cdot$ J. M. Maurer • M. G. G. Sturkenboom

Department of Clinical Pharmacy, University Medical Center Groningen, University of Groningen, Hanzeplein 1, Postbus 30.001, 9700 RB Groningen,

The Netherlands

e-mail: p.n.panday@apoth.umcg.nl

P. Vischjager - M. G. G. Rodgers · M. W. N. Nijsten

Department of Critical Care,

University Medical Center Groningen, University of Groningen, Hanzeplein 1, Postbus 30.001, 9700 RB Groningen, The Netherlands 